\title{
HARGA DIRI DAN AGRESIVITAS PEMBALAP LIAR
}

\author{
Fitrah Imanuddin*
}

*Fakultas Ilmu Pendidikan, Universitas Negeri Jakarta

**Fakultas Ilmu Pendidikan, Universitas Negeri Jakarta

\author{
Burhanuddin Tola**
}

DOI: https://doi.org/10.21009/JPPP.021.03

\begin{abstract}
Alamat Korespondensi:
fitrah_p08@yahoo.com
\end{abstract}

\begin{abstract}
The objectives of this research is to find out self esteem and aggressivity of illegal motorcycle racing that are: profile of illegal motorcycle racers who always make agressivity, factors which cause illegal motorcycle racers do the activities of illegal motorcycle racing, self esteem of illegal racers who always make agressivity, and the impact of self esteem towards illegal motorcycle racers. This research uses a qualitative approach with a case study method of two illegal motorcycle racers who have ten years experience in doing illegal motorcycle racing. This case study was conducted in Bekasi, West Java and Special Jakarta Province starting from 22 October until 22 December 2012. Data was gained through observation and indepth interview. The data was triangulated through crosscheck with all information from other sources before it was analysed qualitatively, i.e. classification of data, coding, examining of the hypothesis, interpretation, and conclusion. The findings of the research are: 1) both illegal racers have two self esteem and aggressivity eventhough they have different indicators, 2) factors causes illegal motorcycle racers who do the illegal motorcycle racing in order to be famous, more respectful and not despiced by other people, have a support from friend, as a kind hobby, and interested in doing challenge referring to the adrenalin, 3) self esteem of illegal motorcycle racers caused their aggresivity due to their self defend, and 4) the impactof self esteem of illegal motorcycle racers is that arise aggressivity, and damaging themselves, society, and other illegal motorcycle racers.
\end{abstract}

\section{Keywords}

self esteem, agressivity, illegal motorcycle racers

\section{Pendahuluan}

Pada akhir-akhir ini kenakalan remaja menjadi masalah utama yang dihadapi oleh masyarakat pada umumnya, aparat keamanan terutama kepolisian. Penyebab utama maraknya kenakalan remaja saat ini adalah karena kurangnya perhatian dan kasih sayang orang tua. Hal ini bisa jadi disebabkan oleh terlalu sibuknya kedua orang tua mereka dengan pekerjaan sehingga perhatian dan kasih sayang kepada anaknya hanya diekspresikan dalam bentuk materi saja. Padahal materi tidak dapat menggantikan dahaga mereka akan kasih sayang dan perhatian orang tua.
Imran (2012) mengatakan kenakalan remaja di era modern ini sudah melebihi batas yang sewajarnya. Banyak anak dibawah umur yang sudah mengenal rokok, narkoba, free sex, dan terlibat banyak tindakan kriminal lainnya. Fakta ini sudah tidak dapat diungkuri lagi, anda dapat melihat brutalnya remaja jaman sekarang. Meningkatnya tingkat kriminal di Indonesia tidak hanya dilakukan oleh orang dewasa, tetapi banyak juga dari kalangan para remaja. Tindakan kenakalan remaja sangat beranekaragam dan bervariasi dan lebih terbatas jika dibandingkan tindakan kriminal orang dewasa. 
Pada dasarnya setiap orang menginginkan dirinya diterima di lingkungan masyarakat maupun lingkungan keluarga, khususnya dari orang tua atau keluarga, karena secara alamiah orang tua dan keluarga memiliki ikatan emosi yang sangat kuat. Pada saat pengakuan, perhatian, pujian, dan kasih sayang tersebut tidak mereka dapatkan di rumah, maka mereka akan mencarinya di tempat lain. Salah satu tempat yang paling mudah mereka temukan untuk pengakuan terebut adalah di lingkungan teman sebayanya. Jarvis (2009) mengatakan kebutuhan kekuatan, penguasaan, kompetensi, kepercayaan diri, kemandirian. Kebutuhan prestise, penghargaan dari orang lain, status, ketenaran, dominasi, menjadi penting, kehormatan dan apresiasi. Sayangnya, kegiatan-kegiatan negatif kerap menjadi pilihan anak-anak tersebut sebagai cara untuk mendapatkan pengakuan eksistensinya.

Salah satu kegiatan yang negatif yang dialakukan oleh para remaja adalah melakukan pembalapan liar. Pada saat ini jumlah pembalap liar di kota-kota besar terus bertambah. Ini dibuktikan dengan seringnya anggota kepolisian melakukan razia pada malam hari di jalan-jalan yang sering dijadikan aksi balapan liar. Dahfaldi (2011) mengemukakan bahwa Polda Metro Jaya berhasil mengamankan 66 orang pembalap liar dihari keempat Ramadan pada saat tertentu. Pembalap-pembalap liar tersebut berhasil dijaring di lima lokasi di seluruh Jakarta. Anggota Reskrim Polres Palu juga berhasil menangkap tujuh remaja yang kerap kali terlibat aksi balap liar dan diduga terlibat melakukan penyerangan rumah warga di Jalan Dr. Wahidin, Minggu pagi tanggal Juli 2011 pagi. Seluruhnya pembalap liar tersebut diamankan pada Selasa tanggal Juli 2011 sekitar pukul 03.00 pagi WITA. Pembalap liar juga terjadi di beberapa tempat lainnya seperti Bekasi, Makassar, Kalimantan, Bandung, Palu, dan lainnya. Balap motor liar yang dikenal dengan 'trek-trekan' marak terjadi sejak tahun 1998 sampai dengan tahun 2005. Pembalap liar seperti masih saja terjadi walaupun polisi telah mengupayakan penertiban.

Pembalap liar tidak pernah jerah untuk melakukan aksinya pada malam hari walaupun pihak berwajib sering menertibkan mereka dan mengadakan razia di tempat-tempat aksi balapan liar. Di Berau, pada tahun 2011, Kasat Lantas
Polres Berau, AKP Siswantoro mengatakan, penertiban merupakan kegiatan rutin yang dilaksanakan Satlantas Polres Berau, sebagai upaya menekan jumlah pelanggaran lalu lintas termasuk aksi kebut-kebutan (Dahfaldi, 2011).Operasi ini merupakan tindak lanjut dari kegiatan penertiban sebelumnya untuk menekan dan menindak para pelaku balapan liar yang tidak pernah jera meski sudah pernah terjaring sebelumnya bahkan mereka telah ditindak. Operasi terhadap balapan liar yang terjadi di berbagai tempat juga sudah mendapatkan dukungan secara resmi dari pemerintah daerah dengan cara mengenakan biaya bagi setiap peserta pembalap liar tersebut. (Pos Kota, Jumat tanggal 8 Agustus 2012).

Balapan liar bukan hanya dilakukan oleh para remaja, tapi juga dilakukan oleh oknum aparat kepolisian bahkan oknum Tentara Nasional Indonesia (TNI). Dalam operasi balapan liar (Pos Kota, 2012).terungkap bahwa petugas berhasil mengamankan dua orang yang diduga anggota TNI yang turut terlibat dalam balapan liar tersebut. Sejumlah anggota pembalap liar lainnya juga berhasil ditangkap petugas di semak-semak saat bersembunyi.

Kota Bekasi misalnya, balapan motor liar sudah semakin meresahkan masyarakat. Untuk menyalurkan hobi anak muda sehingga tidak lari ke balapan liar ini, ketua DPRD Kota Bekasi, Azhar Laena menyelenggarakan balap motor dan mobil. Biaya pendaftaran bagi peserta dikenakan sebesar 325 ribu rupiah bagi dragbikes dan 450 rupiah bagi dragrace dengan hadiah tropi dan uang tunai. Bukan itu saja peserta juga mendapatkan beberapa fasilitas seperti asuransi kecelakaan," tambah, Jefri- Ketua penyelenggara dari Flip Motoracing Devisi (FMD). Tindakan pejabat daerah tersebut tidak membuat para pembalap liar berhenti melakukan aksinya kembali. Sebaliknya, aksi balapan liar di beberapa kota semakin marak. Ini menunjukkan bahwa balapan liar menjadi salah satu masalah yang ditangani secara khusus oleh pihak berwajib dan lingkungan sekitar. Dahfaldi (2011) mengatakan pada akhir-akhir ini mereka mendapatkan perhatian khusus dari pihak berwajib maupun dari masyarakat. Agresivitas para pembalap liar merupakan gejala sosial yang menonjol saat ini sehingga mengundang perhatian berbagai pihak 
seperti orang tua, pendidik, masyarakat, dan lembaga-lembaga pemerintah.
Dari kejadian-kejadian seperti ini, ada beberapa faktor penyebab seseorang melakukan balapan liar, diantaranya seperti pada Tabel 1 .

Tabel 1. Faktor Penyebab Melakukan Balapan Liar

\begin{tabular}{llll}
\hline \multicolumn{3}{c}{ Faktor Penyebab Melakukan Balapan Liar } \\
\hline 1. Faktor Psikologi & a. & Harga Diri & \\
& b. Hobi & \\
& c. Motivasi internal & Berdasarkan hasil \\
& d. & Motivasi eksternal & \\
\hline 2. Faktor Sosial & a. & Teman & \\
& b. & Eksistensi jati diri & \\
\hline 3. Faktor Lingkungan & a. & Tempat bermain & \\
& b. & keuntungan (benefit) & \\
\hline
\end{tabular}

Khisbiyah (dalam Anastasia, 2008), mengatakan bahwa tindakan agresi lebih pada sikap seseorang, sedangkan kekerasan lebih pada perilaku seseorang yang semuanya memiliki faktor penyebab, baik yang berasal dari dalam diri individu maupun dari luar individu. Perilaku agresi merupakan perilaku yang bertujuan untuk menyakiti badan atau perasaan orang lain baik secara verbal maupun secara fisik sehingga merugikan orang lain. Oleh karena itu, perilaku agresi bukan hanya berupa perilaku secara fisik saja, perkataan yang ditujukan kepada orang lain dan mengakibatkan orang lain tersakiti hatinya juga merupakan salah satu bentuk perilaku agresi.

Banyaknya perilaku agresif yang ditimbulkan oleh pembalap liar yang di beritakan di media masa maupun media elektronik semakin membuktikan tingginya tingkat perilaku agresif pada balapan liar, misalnya: pos kota memberitakan “...polisi, Membubarkan trektrekan di Depok II Timur, satpam tersungkur digebuki pembalap liar, Senin tanggal 4 Juni 2012 dini hari”. BekasiRaya.com juga memberitakan tentang balapan liar yang terjadi di daerah Bekasi, "Tawuran terjadi di jalan Chairil Anwar Kota Bekasi, Rabu tanggal 11 Juli 2012 dinihari saat para pemuda melakukan balap liar. Satu gerombolan dari arah Jalan Cut Mutia, dengan mengendarai sepeda motor, nampak melempari batu ke arah gerombolan lain yang membawa bambu-bambu panjang. Tidak ada korban dari bentrokan ini. Namun, kericuhan sempat menimbulkan keriuhan di tempat kejadian".

Tingkah laku sebuah model akan membentuk tingkah laku pada sang pengamat (Koeswara dalam Bandura 1988). Perilaku agresif yang dilakukan oleh model juga akan membentuk agresivitas pada sang pengamat.

Dengan demikian dapat dikatakan bahwa dalam balapan liar, pembalap yang melakukan agresivitas bisa di tiru oleh pembalap lainnya. Hal tersebut akan membuat semakin banyak pembalap yang melakukan tindakan agresif. Pembalap liarpun sering melakukan perdebatan setelah memacu kendaraannya, pemicu perdebatan ini disebabkan oleh kecepatan sampai pada garis finish berbarengan karena tidak jelasnya garis finish balapan liar memicu perdebatan sesama pembalap liar. Setiap pembalap liar tidak pernah ada yang mau mengalah. Hal ini dipicu oleh hasil yang didapat dan harga diri (self esteem) seorang pembalap. Hal tersebut seperti yang diungkapkan oleh Rahmah (dalam Baron dan Byrne, 2003) yang berpendapat bahwa perilaku agresi adalah perilaku yang memiliki tujuan untuk menyakiti secara fisik dan psikis. Banyaknya pembalap tidak takut untuk menyakiti fisik dan psikis orang lain, seperti: memukuli pembalap lain. Penonoton bahkan masyarakat umum menganggap mereka mengganggu. Sering juga masyarakat bertindak sendiri untuk menghakimi pembalap liar aksi balapan liar agar mereka kapok.

Dari tindakan pembalap liar yang menjurus pada prilaku agresivitas ini adanya dorongan keuntungan yang cukup besar untuk diri sendiri maupun untuk kelompok masing-masing bembalap liar. Pembalap tersebut melakukan tindakan agresif karena melihat dan mengikuti pembalap lainnya. Krahe (2000) mengatakan perilaku agresif juga disebabkan pola asuh yang diperoleh melalui proses belajar baik operant 
conditioning maupun proses belajar yang memberikan reward dan punishment, dan juga melalui modelling, yaitu proses belajar melalui observasi terhadap tokoh panutan.

DEPOK (Pos Kota), Satlantas Polrestabes Makassar mencatat enam kasus kecelakaan akibat balap liar yang terjadi di Makassar. "Ada enam korbannya. Semuanya meninggal. Angka ini sangat tinggi. Sementara kita baru masuk di Juni". Sesuai data, pada 2010 lalu terdapat tujuh kasus kecelakaan akibat balap liar. Dari data tersebut, tujuh pelaku balapan liar meninggal di tempat. Dan data yang dihimpun IPW, tahun 2009 di walayah Polda Metro ada 20 lokasi balapan liar. Pada tahun 2012, ada 80 lokasi tempat balapan liar, dan yang terbanyak berada di wilayah Tangerang yaitu sebanyak 21 lokasi. Data IPW terungkap bahwa ada 3 kategori balapan liar yang perilaku buruk, yaitu: geng motor, balapan liar, judi (taruhan), dan tawuran (pengeroyokan), seperti yang dialami seorang anggota TNI AL di Kemayoran. Akibatnya, korban berjatuhan. Pada tahun 2009 tercatat ada 68 orang tewas di arena balapan liar, baik akibat kecelakaan maupun pengroyokan. Tahun 2010 tercata ada 62 orang tewas, dan 2011 ada 65 tewas. Balapan liar yang mereka lakukan kerap mengancam keselamatan masyarakat pengguna lalu lintas. Ada lima lokasi yang menantang yang mereka memiliki, yakni: Warung Buncit dengan tikungan tajam, turunan, dan tanjakan. Rawapanjang, Bekasi, dengan kondisi jalur lurus yang penuh truk dan kontainer, dan di Kemayoran dengan kondisi jalur panjang dan rata, di Kelender yaitu jalur sempit dan gelap, di Asia-Afrika, yaitu jalur pendek dan ada tikungan tajam di Bundaran, sedangkan Pondok Indah adalah jalur bergengsi. Tragisnya, anggota geng motor di arena balapan liar ini masih sangat muda, yaitu berumur antara 14 hingga 22 tahun. Keterlibatan bengkel-bengkel tertentu dalam balapan liar ini sangat menonjol seperti yang dikemukakan oleh (Ramdan, 2012).

Tindakan agresivitas yang dilakukan oleh pembalap liar bukan saja terjadi karena adanya reward yang diperoleh dari hasil balapan liar, akan tetapi pembalap liar juga ingin mendapatkan penghargaan dari teman-temannya maupun dari masyarakat. Pembalap liarpun memikirkan harga dirinya. Jika pembalap tersebut memenangkan aksi balapan liar, mereka bisa mendapatkan perhatian dari teman-temannya. MINGGU sore, 22 Juli lalu, akun Twitter Sapos (@SamarindaPos) dan dragon@sapos.co.id) mengungkapkan bahwa si pembalap juga bisa menggandeng seseorang sebagai pacar.

Mereka melakukan perilaku agresivitas untuk membuktikan kepada diri sendiri dan lingkungan sekitar maupun kepada masyarakat. Pembalap liarpun rela melakukan perilaku agresivitas kepada masyarakat, aparat kepolisian, dan pembalap lainnya untuk membuktikan kalau dirinya sangat berarti, mendapatkan penghargaan dari orang lain, dan mendapatkan perhatian dari lingkungan sekitarnya.

Menurut Kompol Andiyatna (dalam Armi, 2011), selain meresahkan pengguna jalan, pemberantasan balap liar harus dilakukan guna menekan angka kecelakaan dan resiko kematian, serat aksi perjudian yang menjadi salah satu motivasi balap liar.

Melakukan balap liar karena merasa menjadi pusat perhatian. Alasan ini mungkin sama seperti yang dikemukakan oleh Abraham Maslow sebagai "esteem" (harga diri). Seseorang baru merasa benar-benar menjadi "seseorang" setelah melakukan atau mencapai sesuatu, dalam hal ini Amor merasa benar-benar menjadi "seseorang" setelah mampu berbalapan liar dan disaksikan oleh banyak orang. Kata Maslow, pada tahapan "esteem", para Amor mencintai balap liar karena bisa mendapatkan tambahan kepercayaan diri, merasa berhasil melakukan dan mencapai sesuatu (kecepatan), merasa dihormati oleh orang lain. Jika memang benar demikian adanya, maka yang menjadi inti dari maraknya balap liar di Samarinda adalah sensasi psikologi yang mereka rasakan, serta tidak bisa dihilangkan lewat tilang dan larangan semata, dalam akun Twitter Sapos (@SamarindaPos)dandragon@sapos.co.id).

\section{Metode Penelitian}

Penelitian ini menggunakan pendekatan kualitatif. Moleong (2007) mengatakan bahwa penelitian kualitatif adalah upaya untuk menyajikan dunia sosial dan perspektifnya di dalam dunia, dari segi konsep, perilaku, persepsi, dan persoalan manusia yang diteliti. Harga diri (self-esteem) dapat diungkapkan namun secara subyektif sebab setiap individu memiliki permasalahan yang berbeda-beda. Oleh karena 
itu, perlu pendekatan kualitatif yang cocok digunakan untuk memahami tingkah laku dan harga diri pelaku pembalap liar.

Karakteristik subyek adalah remaja yang berjenis kelamin laki-laki dan sudah menjalani peran sebagai pembalap liar lebih dari 5 tahun dan subyek adalah seorang mahasiswa. Penelitian ini memiliki beberapa karakteristik pembalap liar dari hasil wawancara dan observasi terdahulu yang dilakukan oleh peneliti di beberapa tempat balapan liar.

Penentuan subyek penelitian dilakukan secara purposif. Sampel penelitian dipilih berdasarkan kriteria yang sesuai dengan klasifikasi yang diperlukan dan bisa menjelaskan kasus yang diangkat dalam penelitian ini, ketersediaan pembalap untuk dapat diwawancarai, tempat yang dapat dijangkau, dan waktu yang tersedia bagi peneliti.

Jumlah subyek dalam penelitian ini sebanyak 2 orang dengan mempertimbangkan bahwa kedua subjek tersebut memenuhi karakteristik yang telah ditentukan pada penelitian ini.

Dalam penelitian studi kasus ini, peneliti menjaring data dengan menggunakan beberapa teknik yaitu: Observasi, wawancara (interview), dan dokumentasi.

Analisis data dilakukan selama pelaksanaan penelitian dilakukan. Namun, analisis data yang paling banyak dan menentukan data yang bisa digunakan, peneliti menganlisisnya pada akhir pengumpulan data. Karena data penelitian balapan liar ini diprediksi dapat berupa berbagai jenis data yang cukup banyak, maka langkah-langkah yang dilakukan dalam menganalisis data ini, peneliti juga memasukan data dalam komputer dan mengklasifiksi data. Dalam menglasifikasi data tersebut, data tersebut dikelompokan sesuai dengan jenis data, kemudian dipilih data yang sesuai dengan masing-masing jenis. Karena kebanyakan data ini berupa kata-kata dan kalimat, maka kata-kata dan kalimat tersebut disederhanakan dan beberapa bagian yang idenya sama digabung kemudia ditampilkan.

Creswell (2007) mengatakan bahwa analisis data merupakan proses kelanjutan yang membutuhkan refleksi terus menerus terhadap data, mengajukan pertanyaan-pertanyaan analitis, dan menulis catatan singkat sepanjang penelitian. Berikut peneliti melakukan analisis data sesuai dengan prosedur dan tahapan analisis data kualitatif, yaitu:

Mengolah dan mempersiapkan data, membaca keseluruhan data, memberi kode (coding) data, pengujian terhadap dugaan, interpretasi, dan pengecekan keabsahan data.

\section{Hasil Penelitian dan Diskusi}

Menurut Coopersmith (1998) dalam (Widodo, 2008) kekuasaan (power) adalah kemampuan untuk mennggaktur dan mengontrol tingkah laku orang lain. Kemampuan ini ditandai adanya pennggakkuan dan rasa hormat yang diterima individu dari orang lain. Pada situasi tertentu, kebutuhan ini ditunjukkan dengan penghargaan dan penghormatan dari orang lain. Walaupun DR merasakan ketidak enakan jika mengkontrol orang lain dan DR takut diketahui oleh orang tuanya, namun DR tetap melakukan hal tersebut. DR lebih sering mengajak orang yang dikontrolnya bermain dan terus-terusan bermain sampai orang tua yang dikontrolnya mengetahui.

Sama halnya dengan DR, PI juga merasakan tidak enak dengan orang tersebut. PI merasakan ketidak enakan terhadap orang tersebut, namun PI tetap melakukannya. PI melakukannya dikarenakan sudah menjadi tunggaks orang tersebut. Walaupun sudah menjadi tunggaksnya, PI tetap merasakan ketidak enakan terhadap orang tersebut.

Menurut Coopersmith (1998) dalam (Widodo, 2008) keberartian (significance) adalah keberanian individu dalam lingkungan. Hal ini berhubungan dengan penerimaan dan perhatian dari lingkungannya. Semakin banyak ekspresi kasih sayang yang diterimanya, individu akan merasa semakin berarti, tetapi bila individu tidak atau jarang mendapatkan stimulus positif dari orang lain, maka individu tersebut akan merasa ditolak dan kemudian mengucilkan diri dari pernggakulan. DR sangat senang sekali jika dirinya mendapatkan keberanian dari temantemannya ataupun dari orang lain. DR selalu mendiamkan penilaian negatif yang ditujukan kepada dirinya dari orang lain.

Sama halnya dengan DR, PI juga merasakan kesenangan jika diberikan keberanian kepada dirinya. PI merasakan kalau masih ada yang peduli dengan dirinya. PI tidak memperdulikan penilaian dari orang lain, penilaian negatif yang 
diungkapkan oleh orang lain untuk PI tidak dipedulikan oleh subyek.

Menurut Coopersmith (1998) dalam (Widodo, 2008) kebajikan (virtue) adalah ketaatan mengikuti standar moral dan etika, ditandai oleh ketaatan untuk menjauhi tingkah laku yang tidak diperbolehkan. DR tidak memberikan tanggapan tentang hal kebajikan, DR hanya memberikan pendapat orang lain tentang anak motor. DR sangat berat untuk menjauhi tingkah laku yang tidak diperbolehkan, ditambah lagi bermain motor sudah menjadi hobi DR sejak dirinya masih berada di bangku sekolah menengah pertama. DR belum sekalipun menjauhi tingkah laku yang tidak diperbolehkan.

Sama halnya dengan DR, PI pun tidak bisa berkomentar masalah ini. PI menganggap dirinya masih sangat kurang moral dan etikanya. PI pernah berusaha untuk menjauhi tingkah laku yang tidak diperbolehkan, namun bagi PI sangat berat sekali untuk menjauhinya. Perasaaan ingin melakukannya sangat tinggi dan membuat PI selalu ingin mencoba dan mencoba kembali hal tersebut.

Menurut Coopersmith (1998) dalam (Widodo, 2008) kemampuan (competence) adalah sukses memenuhi tuntutan prestasi. Berhubungan dengan kemampuan yang dimiliki individu, dengan adanya kemampuan yang cukup, individu merasa yakin untuk mencapai apa yang dicita-citakannya dan mampu mennggaktasi setiap masalah yang dihadaPI. DR meyakini bahwa prestasi itu sesuatu yang patut dibanggakan sekaligus bermain motor. Kemenangan bagi DR sangatlah penting, kemenangan yang didapat dari hasil bermain motor bisa meningkatkan harga diri DR dan DR juga bisa meninggi pada saat bertemu bengkel lainnya ataupu anak-anak motor. Banyak yang didapat dari hasil kemenangan DR, seperti uang dan harga diri DR yang tinggi. DR sangat kesal jika dirinya mennggaklami kekalahan, bagi DR jika kalah dirinya akan diinjek-injek dan selalu diremehkan oleh orang-orang. Kesennggakn DR saat mendapatkan kemenangan dirasakan juga oleh teman-temannya, setiap kali DR mendapatkan kemenangan, DR selalu mengajak teman-temannya makan-makan. Tujuan DR mendapatkan prestasi agar DR dapat dikenal oleh orang banyak dan bisa lebih dihargai oleh orang lain, dan bisa lebih dihormati oleh orang banyak.
PI meyakini bahwa prestasi itu hanya dimiliki oleh orang-orang yang mempunyai kemampuan lebih, termasuk juga pembalap liar harus dibanggakan, karena tidak semua orang bisa menjadi pembalap liar dan tidak semua orang bisa membawa motor balap. Bagi PI kemenangan sangat lah penting untuk memajukan nama bengkel dan harga diri pembalap dan juga harga diri bengkelnya. PI begitu kesal jika dirinya mennggaklami kekalahan, PI merasa harga dirinya diinjek-injek oleh orang-orang. Kemenangan yang didapat PI membuat dirinya merasakan kesenannggakn yang sangat tinggi, kemenangan yang didapatnya membuat harga dirinya semakin tinggi. Perasaan subyek sangat senang mendapatkan kemenangan, bengkel dan PI tidak selalu diremehkan oleh orang-orang. Tujuan PI ingin menaikan nama bengkel dan PI ingin menjadi terkenal, harga diri PI juga merasa tinggi.

Buss \& Durkee (dalam Aziz, 2006) agresi fisik adalah agresi yang dilakukan untuk melukai orang lain secara fisik. Hal ini termasuk memukul, menendang, menusuk, membakar, dan lainnya. DR jarang sekali untuk berkelahi dalam dunia motor, perkelahian muncul didasarkan karena individunya. Banyak yang dipermasalahkan dalam dunia motor saat sedang main, salah satu permasalahan yang ada dan menimbulkan perkelahian saat motor sampai dinggakris finish bersamaa, kedua orang yang melakukan balapan jarang sekali yang mennggakkui bahwa dirinya kalah. Pada saat itu lah yang memicu perkelahian

Bagi PI perkelahian hanya untuk orang-orang yang tidak mempunyai etika. Dalam hal motor selalu menimbulkan perkelahian. PI pernah berkelahi didalam dunia motor, ditambah lagi kalau sudah menyangkut harga diri pembalap dan bengkel.

Buss \& Durkee (dalam Aziz, 2006) agresi verbal adalah agresi yang dilakukan untuk melukai orang lain secara verbal. Bila seorang mengumpat, membentak, berdebat, mengejek, dan sebagainya, orang itu dapat dikatakan sedang melakukan agresi verbal. DR menganggap kalau agresi verbal sudah biasa di dalam dunia motor, sering bermunculan kata-kata kotor yang dikeluarkan oleh dirinya. Pada saat DR mengalami kekalahan banyak kata-kata kotor yang keluar sambil melakukan perdebetan sesama pembalap. DR selalu saja emosi dalam melakukan 
perdebatan dan kata-kata kotor keluar dari mulut DR seperti: anjing, ngentot, bangsat. DR mengeluarkan kata-kata seperti itu, dikarenakan pada saat melakukan perdebatan kedua belah PIhak tidak ada yang mau mennggakkui kalau dirinya kalah.

Buss \& Durkee (dalam Aziz, 2006) kemarahan (irritability) adalah kemarahan hanya berupa perasaan dan tidak mempunyai tujuan apapun. Contoh seseorang dapat dikatakan marah apabila apabila dia sedang merasa frustrasi atau tersinggung temperamental, kecenderunnggakn untuk cepat marah, kesulitan untuk mengendalikan amarah. DR kesal dan marah jika pada saat DR bermain motor taruhan tidak dibayar oleh lawannya. Beberapa kali DR tidak dibayar oleh musuhnya dan itu membuat DR marah. Jika tidak dibayar DR selalu mengajak lawannya lagi untuk bermain motor atau taruhan, DR selalu mendesak lawannya agar mau bermain lagi dengan dirinya. DR selalu membuat urusannya semakin panjang. Ditambah lagi harga diri yang direndahkan oleh lawannya dengan tidak membayar uang hasil taruhannya.

PI marah jika dirinya dilecehkan oleh orang lain. PI tidak bisa menerima lecehan yang diucapkan oleh orang lain. PI melamPIaskannya keteman-temannya maupun keorang lain. Walaupun disini PI tidak mennggakkuinya, dan PI selalu bilang dirinya hanya menahan jika marah dan tidak mau dikeluarkan, akan tetapi temantemannya merasakan kemarahan PI. Dari hasil catatan lapannggakn PI selalu marah ke temantemannya jika dia marah.

Bus \& Durkee (dalam Aziz, 2006) hostility resentment yaitu cemburu dan iri pada orang lain. DR selalu merasa cemburu jika motor orang lain lebih kencang dari motor dirinya. DR pun menjadi emosi saat melihat ada motor yang olebih kencang. DR pun merasakan kekesalannya.

Sama halnya dengan DR, PI merasa cemburu jika ada motor yang lebih kencang dari dirinya dan jika ada pembalap yang bisa mengalahkan motor yang kencang. Hal itu membuat PI merasa cemburu kepada orang tersebut. Pada saat PI merasa cemburu, PI langsung datang ke mekaniknya untuk membuat motor yang lebih baik dari sebelumnnya, agar PI bisa menang dari motor tersebut.
Buss \& Durkee (dalam Aziz, 2006) hostility suspicion yaitu ketidak-percayaan, kekhawatiran dan proyeksi dari rasa permusuhan pada orang lain; bentuk ekstrim nya adalah menjadi paranoia. Subyek selalu tidak percaya jika ada orang lain yang membicarakan tentang dirinya atau hal yang lain. DR lebih percaya jika ada yang berbicara dihadapannya dibandingka berbicara dibelakang DR. DR pun lebih memilih untuk diam walaupun didalam hati pun DR merasa kesal.

Sama halnya dengan DR, PI pun tidak menghiraukan pembicaraan atau perkataan orangorang. PI lebih percaya jika ada dihadapannya dan PI percaya jika sudah mencobanya. PI juga lebih banyak memilih untuk diam, walaupun PI mencoba dan meyakinkan apakah pendapat orang tersebut benar atau tidak. PI lebih untuk mencari tahu sendiri kebenarannya.

\section{Kesimpulan}

Berdasarkan hasil penelitian bahwa kedua subyek penelitian mempertahankan harga dirinya sehingga kedua subyek menimbulkan agresivitas untuk mempertahankan harga dirinya. Kedua subyek mempunyai keinginan yang sama untuk bisa menjadi terkenal, lebih dihargai orang lain, tidak dilecehkan orang lain, dorongan dari teman, dan kedua subyek menjadi pembalap liar atas dasar hobi mereka menyukai tantangan yang mengacu adrenalin. Kedua subyek memiliki dua aspek harga diri dan agresivitas yang sama, walaupun satu indikator berbeda.

Subyek I tidak pernah untuk menjauhi tingkah laku yang tidak diperbolehkan, dikarenakan subyek I berat untuk menjauhi tingkah laku tersebut, sehingga subyek I terus menerus berada dalam kegiatan balapan liar.

Subyek II pernah berproses untuk menjauhi tingkah laku yang tidak diperbolehkan. Subyek bertahan beberapa bulan untuk tidak melakukannya, pada saat subyek II melakukannya lebih banyak berdiam diri dirumah. Namun subyek II berdiam dirumah hanya makan, tidur, dan nonton tv saja, tidak ada kegiatan lain yang dilakukan oleh dirinya. Namun subyek II ingin terus melakukannya sampai subyek II melakukannya lagi. Subyek II kembali menjadi pembalap liar.

Subyek I selalu menimbulkan agresivitas untuk mempertahankan harga dirinya, keinginan untuk 
terkenalnya menjadi tujuan subyek I menjadi seorang pembalap liar. Harga diri yang dimiliki oleh subyek I sering menimbulkan agresivitas pada saat subyek I kalah bermain motor dan agresivitas sering muncul dirumah, ditempat subyek I berkumpul, dan pada saat subyek I berada di arena balapan liar. Subyek I pun sering melakukan agresi fisik dan agresi verbal kepada orang lain maupun pembalap liar lainnya untuk mempertahankan harga dirinya.

Banyaknya faktor penyebab banyak pembalap liar sekarang ini dan bertahan hingga sekian tahun menjadi seorang pembalap liar, salah satunnya yaitu subyek I. Faktor penyebab utama subyek I menjadi pembalap liar yaitu hobi. Hobi ini datang karena diawali oleh beberapa faktor, seperti : dorongan dari teman, merasa dilecehkan, keinginan untuk terkenal, ingin lebih dihargai, dan uang.

Subyek I mengikuti balapan liar banya dampak dan pengaruh yang terjadi untuk diri sendiri, orang tua, masyarakat, dan lawan atau pembalap liar lainnya. Subyek I tidak memikirkan dampak dan pengaruhnya bagi dirinya, bagi subyek semua itu sudah menjadi resiko bagi dirinya. Mungkin subyek I berani untuk mengambil resiko tersebut, karena keinginan subyek I untuk menaikan harga dirinya hanya bisa dilakukan dengan cara menjadi pembalap liar.

Subyek II sering menimbulkan agresivitas pada saat dirinya berada ditempat kumpul dengan teman-temannya dan pada saat berada di arena balapan liar. Banyaknya agresivitas yang muncul pada saat subyek II melakukan balapan liar, seperti: agresi fisik dan agresi verbal. Subyek II melakukan itu semua untuk menjaga harga dirinya dan nama baik bengkelnya, agar subyek II tidak diremehkan lagi dengan orang lain. Subyek II melakukan agresivitas untuk mempertahankan harga dirinya.

Subyek II sudah bertahan menjadi seorang pembalap liar sekian tahun. Banyaknya faktor penyebab subyek II menjadi pembalap liar, salah satunya adalah hobi. Subyek II menjadikan pembalap liar menjadi hobi dipengaruhi oleh beberapa faktor, seperti :menyukai tantangan yang mengacu adrenalin, dorongan dari teman, keinginan untuk terkenal, mencari teman, merasa dilecehkan, dan uang.
Banyaknya dampak dan pengaruh harga diri pada pembalap liar, salah satunya subyek II. Dampak dan pengaruh harga diri pembalap liar bisa menimbulkan agresivitas. Bukan saja menimbulkan agresivitas saja, harga diri pembalap liar juga bisa merugikan diri sendiri, orang tua, masyarakat, dan lawan atau pembalap liar lainnya. Subyek II juga tidak memikirkan dampak dan pengaruh menjadi pembalap liar, walaupun dampak dan pengaruhnya sangat besar untuk dirinya, orang tua, masyaraka, lawan atau pembalap lainnya.

Pentingnya harga diri bagi kedua subyek tidak menghiraukan nasehat kedua orang tuanya dan membuat kedua orang tunya cemas saat kedua subyek melakukan balapan liar, walaupun berulang kalai orang tuanya menasehati kedua subyek, namun subyek masih menjadi seorang pembalap liar untuk meningkatkan harga dirinya sampai kedua orang tuanya bosan untuk menasehati kedua subyek.

\section{Daftar Pustaka}

Anantasari. (2006). Perilaku Agresif Anak. Yogyakarta: Pustaka Familia.

Andriani, R. (2009). http://eprints.undip.ac.id/ view/Division/Sch=5fpsych/:

http://eprints.undip.ac.id/10668/

Armi, W. (2011). Retrieved Oktober 13, 2012, From http://www.rri.co.id/index.php/Detail berita/ Detail/5051\#.Uh5jt_Slurk

Aziz, S.A. (2006). Mengaplikasi Teori Psikologi Dalam Sukan. Selangor Darul Ehsan. Yeohprinco Sdn.Bhd.

Barbara, K. (2000). Perilaku Agresi. Yogyakarta: Pustaka Belajar.

Baron, R.A, \& Byrne, D. (2004). Psikologi Sosial Jilid 1. Jakarta. (Ratna Djuwita, Melani M. Parman, Dyah Yasmin, Dan Lita P.Lunanta, Penerjemah. Erlangga.

Cast, A.D. (1998). A Theory of Self Esteem. Washington: Washington State University. 
Chaplin, J.P. (2006). Kamus Lengkap Psikologi. I. Jakarta: PT. Raja Grafindo Persada.

Coopersmith, S. (1967). The Antecedent of SelfEsteem. San Fransisco. Freeman \& Company.

Creswell, J.W. (2010). Research Design (Pendekatan Kualitatif, Kuantitatif, Dan Mix Methods). Yogyakarta: Pustaka Belajar.

Dahfaldi, I. (2011). From pedomannews.com: (http://www.pedomannews.com/PilkadaDki-2012/Sosial-Budaya/6080-Ini-JumlahPembalap-Liar-Yang-Berhasil-DiamankanSelama-Ramadan

Geen, R.G. (1998). Human Aggression (Theories, Research,And Implications For Social Policy). San Diego London Boston New York Sydney Tokyo Toronto: Academic Press.

Ghufron, N. (2010). Teori-Teori Psikologi. Yogyakarta: Ar-Buzmedia.

Gray, J.S. (1992). Aggression and Peacefulness in Humans and Other Primates. New York Oxford: Department Of Anthropology University Of Wisconsin-Milwaukee.

Haesty, M.R.D. (2009). Hubungan Antara Harga Diri Dengan Sikap Terhadap Perilaku Seksual Pranikah Pada Remaja Dari Keluarga Broken Home. UMB. Skripsi. Yogyakarta.

Herlinawati, N. (2010). Perilaku Agresif pada Remaja Putri yang Mengalami Abuse oleh Ibu. Skripsi. Fakultas Psikologi.

IPW. (2010). Retrieved 10 13, 2012, From www.docstoc.com

Jarvis, M. (2009). Teori-Teori Psikologi Pendekatan Modern untuk Memahami Perilaku, Perasaan, dan Pikiran Manusia. Bandung. Nusa Media.
Listiyanto, B. D. (2008). Agresivitas Remaja yang Memiliki Orang Tua Tunggal (Single Parent) Wanita. Fakultas Psikologi, Universitas Gunadarma.

Milla, M.N. (2006). Jurnal Psikologi. Yogyakarta: Fakultas Psikologi UGM.

Moleong, L.J. (2007). Metodologi Penelitian Kualitatif. Bandung: PT. Remaja Rosdakarya Bandung.

Njoman, D. (2007). Masalah Orang Tua dan Konformitas terhadap Keikutsertaan Remaja Dalam Balap Motor Liar. Fakultas Psikologi Unika Atma Jaya. Skripsi. Jakarta.

Nugroho, W. (2006). Pengembangan Sirkuit Tawang Mas Semarang Menjadi Sirkuit Balap Mobil . UNDIP.

Prayogo, A. (2009). Perencanaan dan Perancangan Arsitekur (Sirkuit Motor Pemalang). Thesis. Universitas Muhammadiyah Surakarta.

Priliantini, A. (2008). Hubungan Antara Gaya Manajemen Konflik Dengan Kecenderungan Perilaku Agresif Narapidana Usia Remaja Dilapas Anak Pria Tangerang. Jurnal Psiko Edukasi.FKIP Unika Atma Jaya. Skripsi. Jakarta.

Ramdan, D.M. (2012). Retrieved 11 9, 2012, From nasional.kontan.co.id: http://nasional. kontan.co.id/news/60-orang-tewas-pertahun-akibat-geng-motor

Rendra. (2011). Faktor-Faktor Penyebab Remaja Melakukan Balap Liar. Balapan Liar. Abstrak.

Sapariyah, R.A. (2008). Pengaruh Self Esteem, Self Efficacy and Locus of Control Terhadap Kinerja Karyawan dalam Persfektif Balance Scorecard pada Perum Pegadaian Boyolali. Stie Aub Surakarta. 
Sari, C.P. (2009). Jurnal Harga Diri pada Remaja Putri yang Telah Melakukan Hubungan Seks Pranikah. Skripsi. Fakultas Psikologi.

Sitanggang, H. (1994). Kamus Psikologi. Bandung: CV. Armico.

Sriati, A. (2008). Harga Diri Remaja. Fakultas Ilmu Pendidikan, Universitas Padjajaran. Skripsi. Jatinangor.
Subiyantoro, A. (2006). Metode Dan Tekhnik Penelitian Sosial. Yogyakarta.

Walgito. B. (1978). Psikologi Sosial. Yogyakarta. Penerbit Andi.

Widodo, Y.H. (2008). Hubungan Antara Harga Diri Dengan Kecakapan Memimpin. Skripsi. Universitas Sanata Dharma.

Wirawan \& Widyastuti. (2010). Harga Diri Pada Remaja Putri . UPI. 